text long and in parts heavy going for "science and engineering students with a background in physics and engineering at about the sophomore level".

That said, nothing but praise is due to this volume, both for its choice of material and for its presentation. The first two chapters form a résumé of fundamental physical theory, including an outline of wave mechanics, and the motion of electrons in electrostatic fields. The next three chapters discuss the ideal lens and then the practical electrostatic and magnetic lenses, the aberrations of which are dealt with in Chapter 6. The essential features of the electron microscope and its commercial realization are the subjects of Chapters 7 and 8. Chapter 9, one of the most valuable in the book, treats scattering phenomena as a prelude to the discussion of image formation in Chapter 10. The remaining two chapters deal thoroughly with the most important methods of specimen preparation and with typical examples of the applications of the electron microscope.

The text is marked by that elarity which follows from complete familiarity with a subject, and it is illustrated by plenty of excellent diagrams and photographs, remarkable even for this series; at a quick estimate there are some 350 figures, or nearly one por page. Most chapters are followed by problems to test the understanding of the student, and at the end it is a plessure to find such full author and subject indexes. Although there is room, as in any new subject, for differences of opinion on the presentation of some points, such as the alignment of lenses, the book can be unreservedly recommended to all workers in the field, whether they be students or older practitioners; in fact, it is much more of a handbook than an introduction.

\section{E. Cossletet}

\section{MAMMALIAN GERM CELLS}

\section{Mammalian Germ Cells}

Edited by G. E. W. Wolstenholme, assisted by Margaret P. Cameron and Jessie S. Freeman. (A Ciba Foundation Symposium.) Pp. xvi $+302+$ 15 plates. (London: J. and A. Churchill, Ltd., 1953.) 30s. net.

T HIS symposium conducted at the Ciba Founda. tion "for the promotion of international cooperation in medical and chemical research" has assembled thirteen papers concerned with the physiology of spermatozoa and oleven papers concerned with ova. It represents an attempt to bring together in a series of relatively brief presentations recent progress in these rapidly advancing fields. In addition to the formal papers, there is included the discussion of each by the various members of the symposium.

There can be no doubt that the general objective is attained. The various discussions of spermatozoa include analyses of the biochemistry of semen. In a number of instances attempts are made to correlate certain biochemical properties with practical problems in reproduction. For example, there is a critical review of aerobic metabolism in semen and its relationship to fertility in a paper by Dr. C. Terner. Again, Mr. J. C. N. Kol discusses the factors influencing the longevity of bull semen as used for artificial insemination. Of more interest to the physiologist and biochemist are the papers on the biochemical aspects of semen (by Dr. T. Mann), on factors controlling metabolic rates of mammalian spermatozoa (by Dr. H. A. Lardy) and on proteolytic enzymes in human semen (by Dr. F. Lundquist). A fascinating discussion on the movements of spermatozoa by Lord Rothschild reveals hitherto unsuspected hydromechanical relationships. The recent work on the preservation of spermatozoa at extremely low temperatures is informatively presented by Mr. C. Polge. The implications of this low-temperature work for the general problems of mammalian fertility and the preservation of desirable genetic characteristics are most fascinating. The practical implications of spermatozoology in human health and disease are ably presented by Dr. J. MacLeod.

Investigations of mammalian ova described in this volume are concerned with : $(a)$ ovulation, $(b)$ ovum maturation, $(c)$ ovum transplantation, $(d)$ in vitro studies with mammalian eggs, $(e)$ early developmental physiology, and $(f)$ medical problems relating chiefly to the ovum and pregnancy. As in the case of the spermatozoa, the problem of the longevity of the mammalian egg is touched upon in practically every phase of these investigations. This is especially apparent in the paper by Dr. S. A. Asdell on the effect of controlled ovulation upon the fertility of the mammalian egg, the paper by Dr. M. C. Chang on the fertilizability of rabbit germ cells and a paper by Dr. L. F. Casida on factors affecting fertilization and embryonic death. One of the chief mysteries relating to the development of the mammalian ovum is the problem of fertilization in vitro. This is discussed particularly in the paper by Mr. O. Venge, but forms part of the discussion of a number of the papers. The great difficulty experienced by a number of investigators in consistently effecting fertilization in vitro is emphasized. The experiments of Audrey U. Smith on the effects of low temperature on rabbit eggs signalize another field of experimentation which parallels similar work with spermatozoa. The transplantation of ova subjected to various experimental conditions is ably reviewed by Mr. C. E. Adams as well as by Dr. Chang. The clinical aspects are presented in papers by Dr. P. N. F. Bishop and Dr. Ian Donald.

It is, of course, not possible to present criticism of the numerous experimental details contained in this assemblage of papers. I find the presentation of sperm biochemistry comprehensive and adequate. The biochemistry of the egg is much less well established. For example, the knowledge of enzymatic transformations and the carbohydrate metabolism of sperm has no counterpart in ovum investigations. This may be due in part to the need for the development of adequate micro methods for use with the limited number of ova available for study. There is only tangential discussion of the role of hormones as regulators of sperm and ovum physiology. Although it is clear that some of the effocts of the gonadal hormones may be indirect, nevertheless it would have been useful to have set forth their function in creating specific environments for spermatogenesis, ovulation, fertilization and early development.

There can be no question of the great usefulness of this volume to active investigators in the field of mammalian germ cells. It should be of fundamental interest also to persons interested in the problems basic to modern animal husbandry. Although in no sense a book for the medical practitioner, the thoughtful physician interested in problems of fertility and sterility should find this symposium informative and stimulating.
Gregory Pincus 